\title{
Evaluation of Development Aspects on the Implementation of Field and Institutional Performance Dashboards at LPKA Class I Palembang
}

\author{
Hendra Hadiwijaya ${ }^{1}$, Febrianty (2) $^{*}$, Rezania ${ }^{3)}$ \\ ${ }^{1) 2}$ Politeknik Palcomtech, ${ }^{3)}$ STMIK Palcomtech, Indonesia \\ ${ }^{1)}$ h2.wijaya@gmail.com, ${ }^{2) *}$ febrianty@palcomtech@ac.id, ${ }^{3)}$ rezania@palcomtech.ac.id
}

Submitted : Oct 1, 2021 | Accepted : Oct 30, 2021 | Published : Nov 14, 2021

\begin{abstract}
LPKA Class I Palembang is an institution that enforces the Integrity Zone, WBK, and WBBM. Therefore, one of the technological innovations that will support the implementation is to instill a data-based performance culture through the LPKA Class I Palembang Dashboard. The purpose of this study is to evaluate the development of the dashboard model of government institutions in this case monitoring and reporting on the performance of the fields at LPKA. This evaluation will be included in the development of the dashboard in order to provide optimal net benefits for the management of LPKA Class I Palembang. The research was conducted in 4 stages, namely: determining the research design, identifying dashboard needs, identifying indicators in the development of the Palembang Class I LPKA dashboard model, and formulating a dashboard development model. The dashboard development model was formed based on the results of literature studies and surveys conducted on prospective dashboard users at LPKA Class I Palembang. The survey was conducted on prospective dashboard users, namely structural officials, General Functional Positions, and Certain Functional Positions with a total of 102 employees. The sampling technique is purposive sampling as many as 60 people were directly involved in reporting field performance. The evaluation of the aspects of the LPKA Dashboard shows that from the aspect of presenting Data/Information there are weaknesses in the visual display that is not yet rich in graphics, the unavailability of facilities for predicting future performance conditions, and facilities for causal analysis. The results of this study state that for the aspect of collaboration between users, the benefits that have not been felt are more, namely the exchange of information between users and no conference facilities are available. Meanwhile, in the dashboard performance aspect, there is no link to the administrator.
\end{abstract}

Keywords: LPKA Class I Palembang, Dashboard, Field Performance, Institutional Performance

\section{INTRODUCTION}

Performance dashboards are multilayer applications built for business intelligence and data integration infrastructure that enable organizations to measure, monitor and manage business performance more effectively" (W. Eckerson, 2006). Dashboards are designed around two types: business intelligence and performance control. Performance dashboards can be seen as a new generation of performance monitoring systems based on integrated business intelligence and data infrastructure with the aim of ensuring, measuring, and controlling the running of business processes in the company (I.Petkovic et al, 2009). The dashboard provides various statistics and conclusions that make it easier for management to make decisions. So, dashboards generally present in the form of presentations, search features, visualization features, graphs and metrics/statistical tabs, graphical trend analysis, capacity meters, geographic maps, and others. Presentation of statistical figures in the form of ratios, percentages, variances, and others that makes it very easy to read comprehensive and integrated data and information and get it faster. Dashboards can play an important role in measuring and improving performance as they provide the documentation or evidence as well.

*name of corresponding author 
Every company/institution will take advantage of the development of information technology to increase their productivity and business value (P. Chowdhary et al, 2006). The existence of the company will greatly depend on the speed and accuracy of the company in making decisions regarding current business conditions and those related to strategic issues of the company. In the implementation of strategic management, a control mechanism is needed that functions to ensure the achievement of the company's strategy (David, 2005). Therefore, the most suitable type of dashboard will depend on the needs of the company/institution and the performance of different tasks. Likewise, the Class I Palembang Special Child Development Institute (LPKA), which is an institution that is in the post-adjudication stage, plays a role in providing guidance to protect the human rights of Correctional Students (Andikpas). LPKA conducts training that aims to prevent "prisonization" which is a learning process in prison culture that can actually make a person's condition (andikpas) worse than before he was admitted to prison. Because as a government institution, the implementation of service performance and institutional governance performance is highly demanded to implement good governance and must support the implementation of the Integrity Zone (ZI), Corruption Free Area (WBK), and Clean Serving Bureaucratic Area (WBBM). Thus, monitoring service performance and institutional performance becomes a priority for LPKA Class I Palembang. LPKA Class I Palembang employees consist of 15 structural officers, 81 General Functional Positions (JFU), and 6 Specific Functional Positions (JFT), bringing a total of 102 employees (LPKA Class I Palembang Employment Data, 2018). In the context of efficiency and effectiveness in reporting performance, LPKA Class I Palembang uses dashboard technology innovation with the URL http://e-dashboardlpkapalembang.sumselprov.go.id/ in addition to using the e-journal application.

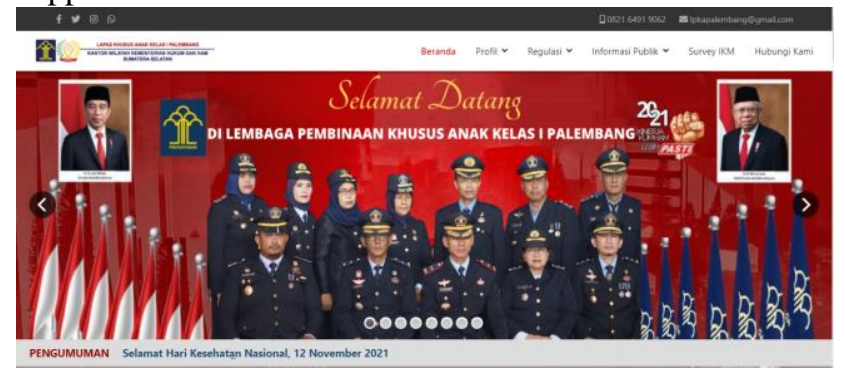

Figure 1. Display of the Homepage of the Web page of LPKA Class I Palembang http://lpkapalembang.kemenkumham.go.id/

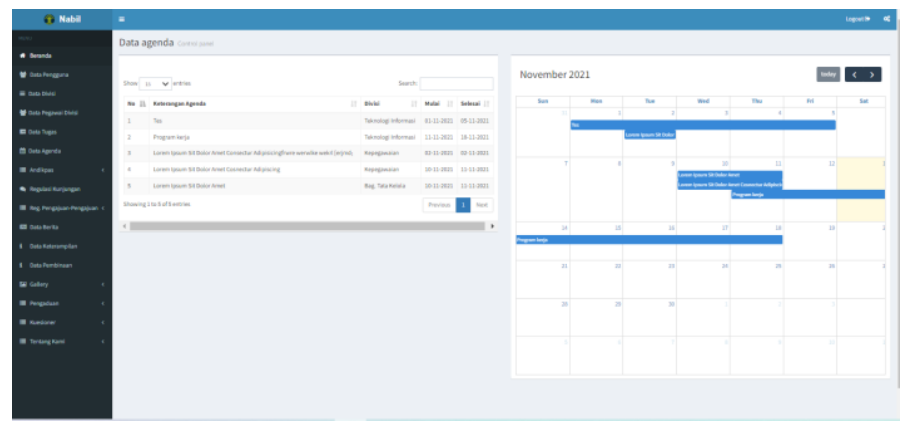

Figure 2. Display of Agenda Data on the Performance Dashboard of Class I LPKA Palembang

Performance dashboards in an institution are a way to instill a culture of measurable performance and can improve the efficiency of a decision-making process (O. Hanselman, 2006). Doerfel defines a dashboard as "a set of financial indicators and other operational measures that reflect key elements of an entity's strategic direction implemented to "navigate" the organization, much like a pilot constantly monitoring and navigating an aircraft through a series of indicators in the cockpit" (M. Doerfel, 2002). Thus, the use of the performance dashboard will be very useful for company management in monitoring the company's performance and making strategic decisions more effectively in accordance with these conditions. Company performance is the overall success of the company in achieving the strategic goals that have been set through selected strategic initiatives (Nugrahayu, 2015). Company performance is defined as the company's ability to achieve its goals through efficient and effective use of resources and describes how far a company achieves its results after being compared to previous performance, previous performance, and other organizational performance benchmarking, as well as to what extent it achieves the goals and targets that have been set (Nugrahayu, 2015)

The results of the study (Ghazisaeidi, 2015) resulted in the main steps for developing a dashboard for performance management purposes. Performance dashboards developed based on performance measurement *name of corresponding author 
principles and executive information systems and supported by the right back-end infrastructure will result in the creation of dynamic reports that help healthcare managers to measure performance consistently, continuously detect deviations, deeply analyze the causes of performance the bad, and effectively plan for the future.

The purpose of this study is to evaluate the development of the dashboard model of government institutions in this case monitoring and reporting on the performance of the fields at LPKA Class I Palembang. This evaluation will be included in the development of the dashboard in order to provide optimal net benefits for the management of Class I LPKA Palembang.

\section{LITERATURE REVIEW}

\section{Performance Dashboard Basic Model}

Malik (2005) developed a performance dashboard model, suggesting the need for mapping for information, users, and percentages (Figure 1). The information needed by the company is all data that must be owned by the performance dashboard data store so that the performance dashboard function can be more effective and present the company's condition. The definition of information needs is done by documenting all KPIs owned by the company/business unit.

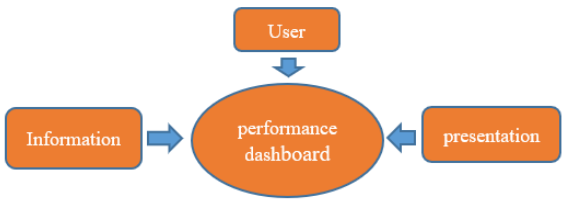

Figure 3. Basic Model of Performance Dashboard

The specified performance dashboard users can be grouped based on the three types of performance dashboards proposed by (W. Eckerson, 2006), namely strategic dashboards used for top-level management, tactical/managerial dashboards for middle-level management, and operational dashboards for lower-level management. In designing the presentation of performance dashboard data, it is necessary to consider elements of design, layout, and navigation, as well as support for business intelligence according to company needs. Dashboards with Business Intelligence (BI) dashboards provide information for company executives to know what is going on in each section/division in the company by providing the results of processing a lot of information presented on one dashboard display screen with easy-to-understand graphs (T. Bray, 2011).

Research (Devender Maheshwari and Marijn Janssen, 2014) shows that the effectiveness of the dashboard is highly dependent on the implementation decisions made. Incorporating multiple views to explain diversity in public values is critical to success. They recommend doing more research on the use of dashboards in the public sector, especially the use of dashboards to engage civil society.

(Lafortune, 2018) argue that the lack of consensus on and the complexity of conceptualizing what constitutes "good governance" requires a dashboard approach to indicator development in government agencies. Therefore, it needs to be adjusted to the needs of the institution and the level of the user.

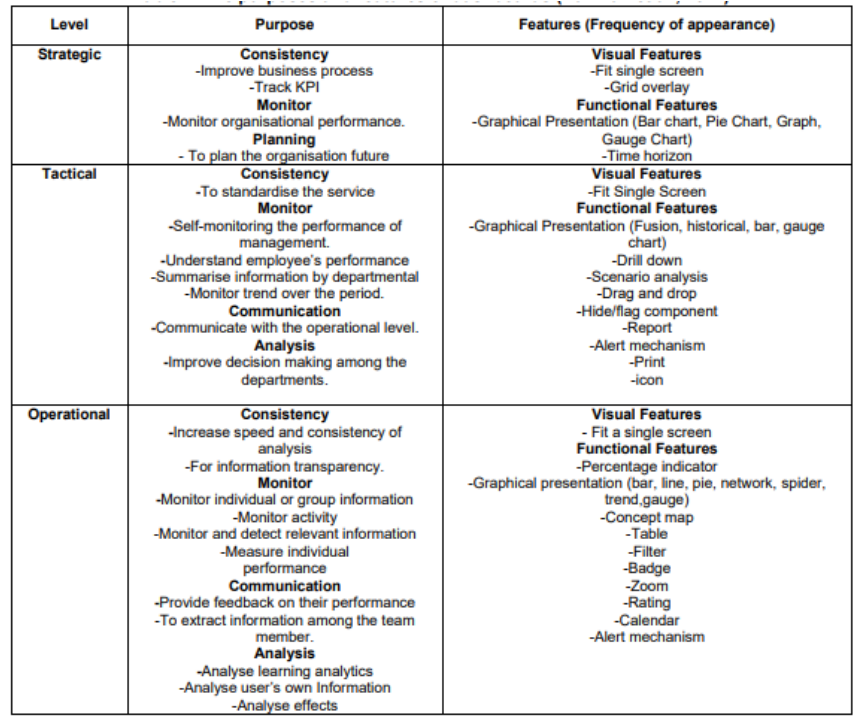

Table 1. The purposes and features of dashboards

Source: (Rahman, 2017)

*name of corresponding author 
Some of the major advantages are to identify dashboard objectives based on the targeted managerial level and features that meet these goals (Rahman, 2017). The main distinct purpose of using dashboards is the ability to ensure consistency, planning, communication, and monitoring (Pauwels, 2009); (Rahman, 2017).

\section{Dashboard and Decision Making}

The dashboard is proposed as a support mechanism that allows facilitating various avenues of decision making, such as measuring product life cycle sustainability and consumption levels (Traverso, 2012). In other words, nonexperts who are targeted by experts and scientists are part of the decision-making process, this clear presentation of information is a requirement (Traverso, 2012), which reinforces the importance of using tools such as assistive devices. dashboard to sort and utilize data effectively (Donhost, 2007). Moreover, the emergence of distributed decision-making has increased the importance of examining the influence of decisions made by operational-level managers, not just executives (March, 2007).

\section{Dashboard and Performance Measurement}

It is very important for every organization to measure and improve its performance. The ability to measure performance numerically offers accurate data that facilitates analysis, helping to improve organizational quality (Arora, 2015). For example, dashboards used in the clinical sector are more effective than electronic medical records (EMR) and computerized decision support systems (CDSS) by providing summary performance measurements and enabling data visualization (Dowding, 2015)

\section{METHOD}

The research was conducted in 4 stages, namely: determining the research design, identifying dashboard needs, identifying indicators in the development of the Palembang Class I LPKA dashboard model, and formulating a dashboard development model. As illustrated in Figure 4., below:

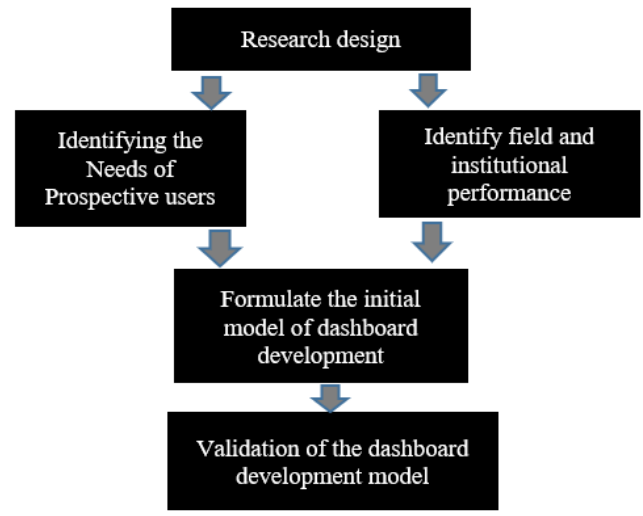

Figure 4. Research Stages

The dashboard development model was formed based on the results of literature studies and surveys conducted on prospective dashboard users at LPKA Class I Palembang. The survey was conducted on prospective dashboard users, namely structural officials, General Functional Positions (JFU), and Certain Functional Positions (JFT) with a total of 102 employees. The sampling technique is purposive sampling as many as 60 people are directly involved in reporting field performance. With the following details: General Sub Division (5 people), Employee Affairs and TU (5 people), Financial Affairs and Equipment (5 people), Registration and Classification Section (9 people), Development Section (15 people), Maintenance Section (9 people), Section for Supervision and Discipline enforcement (12 people). The questionnaire refers to 4 (four) aspects of needs that are identified and analyzed, including needs related to aspects of data/information presentation, personalization, a collaboration between users, and dashboard performance (Hariyanti, Eva, 2008).

Determination of field performance indicators and institutional performance is carried out by referring to the Institution's Tarja (Work Targets) because field performance must refer to the performance of the institution. Because it is still in the early stages, the dashboard is made as simple as possible in advance so that it can instill a data-based culture for monitoring institutional performance. This is based on the results of the FGD (Focus Group Discussion). Field performance indicators and institutional performance are expressed in the number of work program realizations in total (done, on progress, cancel, rescheduled, and extension/past time) and percentage compared to the set target.

*name of corresponding author 


\section{RESULT}

The Palembang Class I LPKA dashboard can be found at http://e-dashboardlpkapalembang.sumselprov.go.id/. This dashboard is not only for the performance of fields and institutions but is also integrated with the performance of visiting services and other services, namely Remission, Assimilation, Family Visiting Leave (CMK), Conditional Release (PB), Before Free Leave (CMB), and Conditional Leave (CB).

In developing the performance dashboard model of Class I LPKA Palembang, it will pay attention to the aspects of data/information presentation, personalization, a collaboration between users, and dashboard performance. Therefore, it is still in its early stages, the dashboard is still kept simple. The field performance dashboard will show that users are on a tactical level and a strategic level.

Table 2. Users of the Field and Institutional Performance Dashboard at LPKA Class I Palembang

\begin{tabular}{|c|c|}
\hline Level & Position/Section \\
\hline \multirow{4}{*}{ Strategic } & Head of LPKA Class I Palembang \\
\hline & Head of General Subdivision \\
\hline & Ka. Employee Affairs and TU \\
\hline & Ka. Financial Affairs and Equipment \\
\hline \multirow{4}{*}{ Tactical } & Head of Registration and Classification Section \\
\hline & Head of Development Section \\
\hline & Head of Maintenance \\
\hline & Head of Supervision and Discipline Enforcement Section \\
\hline \multirow{8}{*}{ Operational } & Registration subsection \\
\hline & Assessment and Classification Subsection \\
\hline & Education and Skills Training Subsection \\
\hline & $\begin{array}{l}\text { Subsection of Food, Beverage and Equipment Services for } \\
\text { Prisoners }\end{array}$ \\
\hline & Health Service Subsection \\
\hline & $\begin{array}{l}\text { Subsections of Administration and Supervision and } \\
\text { Discipline Enforcement }\end{array}$ \\
\hline & Security Squad \\
\hline & Functional Position Group \\
\hline
\end{tabular}

Based on Table 2. it can be seen that user classification will affect data and information needs in reporting and decision making. Results Based on the questionnaire obtained that for the aspects of data/information presentation, personalization, a collaboration between users, and dashboard performance, the recapitulation is presented as follows:

Table 3. Recapitulation of Respondents' Answers for Dashboard Development Needs Performance of Fields and Institutions of Class I LPKA Palembang

\begin{tabular}{|c|c|c|c|}
\hline Information & Statement & Answer & Percentage \\
\hline \multirow{8}{*}{$\begin{array}{l}\text { Presentation of } \\
\text { Data/Information }\end{array}$} & Graphically rich visual display & 29 & 48,33 \\
\hline & Synergistic information presentation in one screen & 55 & 91,67 \\
\hline & high accuracy of information & 56 & 93,33 \\
\hline & Presentation of information in stages & 58 & 96,67 \\
\hline & Show previous performance history & 53 & 88,33 \\
\hline & Facility for prediction of future performance conditions & 0 & 0,00 \\
\hline & Cause-and-effect analysis facility & 0 & 0,00 \\
\hline & Real-time information & 58 & 96,67 \\
\hline \multirow{6}{*}{ Personalization } & Information is presented specifically according to the user's & 57 & 95,00 \\
\hline & High level of information privacy & 59 & 98,33 \\
\hline & Size/metric customization & 56 & 93,33 \\
\hline & Customize the use of performance standards & 56 & 93,33 \\
\hline & Customize chart type & 58 & 96,67 \\
\hline & Customize content-type/information content & 56 & 93,33 \\
\hline \multirow{6}{*}{$\begin{array}{l}\text { Collaboration } \\
\text { between users }\end{array}$} & Exchange of information between users & 32 & 53,33 \\
\hline & $\begin{array}{l}\text { Communication function support for management and } \\
\text { control }\end{array}$ & 58 & 96,67 \\
\hline & Communicating goals and strategies & 57 & 95,00 \\
\hline & Alert for alert & 59 & 98,33 \\
\hline & Active exchange of information & 58 & 96,67 \\
\hline & Conference facilities & 0 & 0,00 \\
\hline \multirow{7}{*}{$\begin{array}{c}\text { Dashboard } \\
\text { Performance }\end{array}$} & Fast response time & 57 & 95,00 \\
\hline & Easy navigation availability & 55 & 91,67 \\
\hline & Interaction with other systems & 53 & 88,33 \\
\hline & Database can expand & 58 & 96,67 \\
\hline & Stable response speed & 57 & 95,00 \\
\hline & Small failure percentage & 59 & 98,33 \\
\hline & Clear access rights & 59 & 98,33 \\
\hline
\end{tabular}

*name of corresponding author 


\begin{tabular}{|l|l|c|c|}
\hline & Easily modify appearance & 55 & 91,67 \\
\cline { 2 - 4 } & Dashboard socialization training & 54 & 90,00 \\
\cline { 2 - 4 } & Link to administrator & 0 & 0,00 \\
\cline { 2 - 4 } & Selection of access features via intranet/internet & 60 & 100,00 \\
\hline
\end{tabular}

Source: Processed from the questionnaire, 2021

Based on Table 3. Above, there are several items that are still not available, and some items that are felt to have not functioned properly as expected were only $48.33 \%$. From the aspect of presenting data/information for visual display, it is not yet rich in graphs because what is available is still bar graphs and pie charts, so improvements are needed to add various types of visuals that help decision making. Facilities for predicting future performance conditions and causal analysis facilities are not yet available, even though these facilities are important for accelerating management decision-making for Class I LPKA Palembang. Therefore, the developer will make a simulation between the Work Target and Realization with a timeline that does not contain a large gap.

In the aspect of collaboration between users, it is still felt that the percentage is still $53.33 \%$. This is an input for application developers to facilitate the exchange of communication between sections and communication facilities are available to exchange and share information in the form of chat. In addition, conference facilities are not yet available on the dashboard. Meanwhile, in the dashboard performance aspect, there is no link to the administrator. The following is a login display to the LPKA Class I Palembang Dashboard, where access rights are divided into super admin, leadership, section head, employees, news admin, complaint admin, questionnaire admin, andikpas admin, coaching admin, and andikpas family.

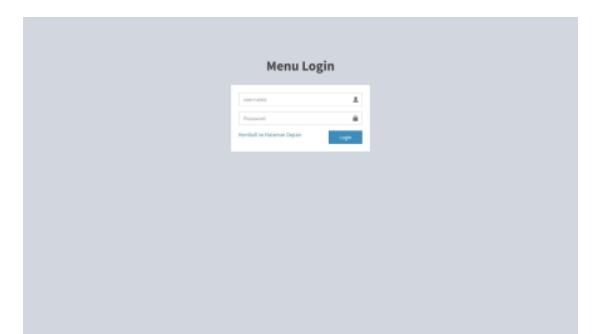

Figure 5. Dashboard users are Heads of LPKA Class I Palembang

The dashboard user display and the number of employees in each section as well as the display of inputting the agenda or work program are presented below:
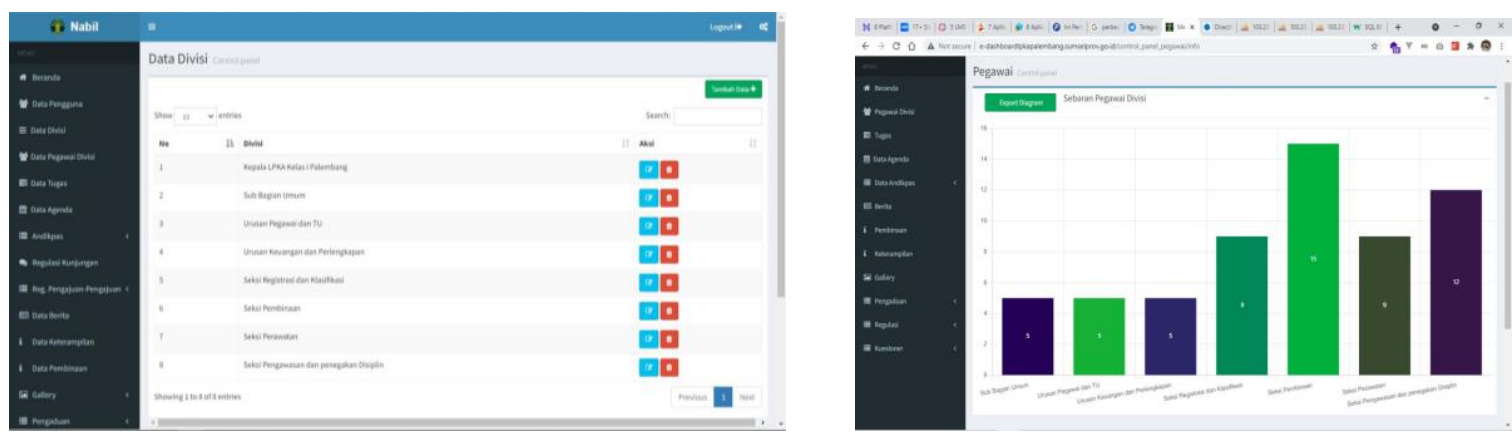

Figure 5. Dashboard users are Heads of LPKA Class I Palembang

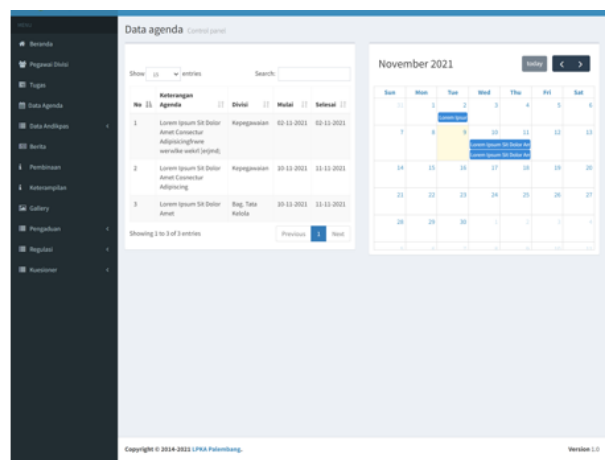

Figure 6. Visual of input agenda or work program

*name of corresponding author 


\section{DISCUSSIONS}

The LPKA Class I Palembang dashboard will also be developed for android based so that it is more effective and efficient. In its implementation, this dashboard has provided benefits even though its implementation is still under 6 months but some benefits are felt. The following are the results of the recapitulation of the answers of 60 respondents who are management ranks related to the perceived benefits of implementing the Palembang Class I LPKA dashboard.

Table 4. Recapitulation of Respondents' Answers to the Benefits of Field and Agency Performance Dashboards for LPKA Class I Palembang

\begin{tabular}{|c|c|c|c|}
\hline No & Statement & Answer & percentage \\
\hline 1 & $\begin{array}{l}\text { The dashboard helps you to identify problems } \\
\text { quickly }\end{array}$ & 35 & 58,33 \\
\hline 2 & $\begin{array}{l}\text { Dashboards support you to make individual } \\
\text { decisions quickly }\end{array}$ & 32 & 53,33 \\
\hline 3 & $\begin{array}{l}\text { Dashboards support you to do extensive problem } \\
\text { analysis }\end{array}$ & 45 & 75,00 \\
\hline 4 & $\begin{array}{l}\text { Dashboards help you to share your organization's } \\
\text { vision, goals, and strategies with other users }\end{array}$ & 53 & 88,33 \\
\hline 5 & $\begin{array}{l}\text { Dashboards help you to make decisions about your } \\
\text { organization effectively }\end{array}$ & 47 & 78,33 \\
\hline 6 & $\begin{array}{l}\text { Dashboards foster user awareness to access } \\
\text { information, so as to increase productivity or } \\
\text { organizational performance }\end{array}$ & 56 & 93,33 \\
\hline 7 & $\begin{array}{l}\text { The dashboard can be a solution to realize good } \\
\text { governance }\end{array}$ & 53 & 88,33 \\
\hline 8 & $\begin{array}{l}\text { The dashboard can actualize the implementation of } \\
\text { ZI, WBK, and WBBM. }\end{array}$ & 59 & 98,33 \\
\hline
\end{tabular}

Based on Table 4. it can be seen that there have been benefits, although they are still not significant, it can be seen from the responses of respondents to the implementation that has been carried out. Especially in the statement that the Dashboard raises user awareness to access information, so as to increase productivity or organizational performance by $93.33 \%$ and the statement that the Dashboard can actualize the implementation of ZI, WBK, and WBBM by $98.33 \%$.

\section{CONCLUSION}

The evaluation of the aspects of the LPKA Class I Palembang Dashboard shows that from the aspect of presenting Data/Information there are weaknesses in the visual display that is not yet rich in graphics, the unavailability of facilities for predicting future performance conditions, and facilities for causal analysis. For the aspect of collaboration between users, the benefits that have not been felt are more, namely the exchange of information between users and no conference facilities are available. Meanwhile, in the dashboard performance aspect, there is no link to the administrator. This model for developing field and institutional performance dashboards will be a solution to realize good governance and the implementation of ZI, WBK, and WBBM. However, the success of implementing technological innovations in an institution is very dependent on the support of top management to make optimal use of it so that the results are visible and data-based performance culture is embedded. Further research needs to evaluate the success factors of the performance dashboard, especially for government agencies and public service institutions.

\section{ACKNOWLEDGMENT}

The researcher would like to thank Ristekdikti-BRIN for funding this research with contract number 1406/SP2H/LT/LL2/2021. This research is applied research in the second year of 3 years of funding. The researcher is also grateful for the cooperation of partners, namely LPKA Class I Palembang, both to the leadership of LPKA Class I Palembang Mr. Tri Wahyudi, Bc.IP, S.H., and all staff.

\section{REFERENCES}

Arora, A. \&. (2015). Performance assessment model for management educators based on KRA/KPI. International conference on technology and business managemen.

David, F. (2005). Strategic Management: Concepts and Cases. 10th ed, New Jersey: Prentice Hall.

Devender Maheshwari and Marijn Janssen. (2014). Dashboards for supporting organizational development. In principles for the design and development of public sector performance dashboards (pp. 178-185). New York:

*name of corresponding author 
Proceedings of the 8th International Conference on Theory and Practice of Electronic Governance (ICEGOV '14) Association for Computing Machinery.

Donhost, M. J. (2007). Data-driven decision making. Middle School Journal, Vol. 42 56-63.

Dowding, D. R.-M. (2015). Dashboards for improving patient care: review of the literature. . International journal of medical informatics, 87-100.

Ghazisaeidi, M. S. (2015). Development of Performance Dashboards in Healthcare Sector: Key Practical Issues. Acta informatica medica : AIM : journal of the Society for Medical Informatics of Bosnia \& Herzegovina : casopis Drustva za medicinsku informatiku BiH, 317-321.

Hariyanti, Eva. (2008). Metodologi Pembangunan Dashboard Sebagai Alat Monitoring Kinerja Organisasi Studi Kasus: Institut Teknologi Bandung”. Bandung: Tesis Magister Informatika. ITB.

I.Petkovic et al. (2009). Performance Scorecard for Electric Power Distribution. IEE.

Lafortune, G. \&. (2018). Government at a Glance: A Dashboard Approach to Indicators. 10.1007/978-3-31962707-6_9.

M. Doerfel. (2002). Benchmarking in higher education. In Becoming more adaptive, innovative and interactive organizations, Using Benchmarking to Inform Practice in Higher Educatio (pp. No. 118 Hal 3-25). Bender, B and Schuh, $\mathrm{H}$.

March, S. T. (2007). Integrated decision support systems: A data warehousing perspective. Decision Support Systems.

Nugrahayu, E. R. (2015). enerapan Metode Balance Scorecard sebagai Tolak Ukur Pengukuran Kinerja Perusahaan. Jurnal Ilmu dan Riset Akuntansi, 1-16.

O. Hanselman. (2006). Uniting Strategy With Action Using a "Performance Dashboard. Performance Management, 35-46.

P. Chowdhary et al. (2006). Model-Driven Dashboard for Business Performance Reporting. In IBM.T.J. Watson Research Center.

Pauwels, K. A. (2009). Dashboards as a service: why, what, how, and what research is needed? Journal of Service Research, Vol. 12 Hal 175-189.

Rahman, A. A. (2017). Review on dashboard application from managerial perspective. In Research and Innovation in Information Systems (ICRIIS) (pp. 1-5). International Conference on.

T. Bray. (2011). The Role of Business Intelligence Dashboards in Financial Management. Credit Control Journal, Vol. 32 Hal 1-5.

Traverso, M. F. (2012). Life Cycle Sustainability Dashboard. Journal of Industrial Ecology, 680-688.

W. Eckerson. (2006). Performance Dashboards. In Measuring, Monitoring and managing your business. Hoboken, NJ: Wiley. 